26 Coxhead CE, Inskip H, Meade TW, North WRS, Troup JDG. Multicentre trial of physiotherapy in the management of sciatic symptoms. Lancet $1981 ;$ i: $1065-8$.

27 Waagen GN, Haldeman S, Cook G, Lopez D, DeBoer KF. Short term trial of chiropractic adjustments for the relief of chronic low back pain. Manual Medicine 1986;ii:63-7.

28 Hoehler GK, Tobis JS, Buerger AA. Spinal manipulation for low back pain. FAMA 1981;245:1835-8.

29 Sims-Williams H, Jayson MIV, Young SMS, Baddeley H, Collins E. Controlled trial of mobilisation and manipulation for patients with low back pain in general practice. BMF 1978;ii:1338-40.

30 Zylbergold RS, Piper MC. Lumbar disc disease: comparative analysis of physical therapy treatments. Arch Phys Med Rehabil 1981:62:176-9.

physical therapy treatments. Arch Phys Med Rehabil 1981;62:176-9. Postacchini F, Faccini $M$, Palieri P. Efficacy of various forms of
conservative treatment in low back pain: a comparative study. Neuro-

32 Rasmussen GG. Manipulation in treatment of low back pain: a randomized clinical trial. Manual Medicine 1979;i:8-10.

33 Farrell JP, Twomey L.T. Acute low back pain: comparison of two conservative treatment approaches. Med f Aust 1982;1:160-4.

34 Nwuga VCB. Relative therapeutic efficacy of vertebral manipulation and conventional treatment in back pain management. Am $\mathcal{F}$ Physical Med 1982;1:160-4.

35 Waterworth RF, Hunter IA. An open study of diflunisal, conservative and manipulative therapy in the management of acute mechanical low back pain. $N Z$ Med $\mathcal{F} 1985 ; 98: 372-5$.

36 Arkuszewski $Z$. The efficacy of manual treatment in low back pain: a clinical trial. Manual Medicine 1986;ii:68-71.

37 Buerger AA. A controlled trial of rotational manipulation in low back pain. Manual Medicine 1980;ii:17-26.

38 Tobis JS, Hoehler FK. Musculoskeletal manipulation in the treatment of low back pain. Bull N Y Acad Med 1983;7:660-8.

39 Brontfort GDC. Chiropractic versus general medical treatment of low back pain: a small scale controlled clinical trial. American fournal of Chiropractic Medicine 1989;2:145-50.

40 Kinalski R, Kuwik W, Pietrzak D. The comparison of the results of manual therapy versus physiotherapy methods used in treatment of manual therapy versus physiotherapy methods used in treatment of
patients with low back pain syndromes. Manual Medicine 1989;iv: 44-6.
41 Godfrey CM, Morgan PP, Schatzker J. A randomized trial of manipulation for low-back pain in a medical setting. Spine 1984;9:301-4.

42 Siehl D, Olson DR, Ross HE, Rockwood EE. Manipulation of the lumbar spine with the patient under general anesthesia: Evaluation by electromyography and clinical-neurologic examination of its use for lumbar nerve root compression syndrome. Fournal of the American Osteopath Association 1971;70:433-40.

43 Rupert RL, Wagnon R, Thompson P, Ezzeldin MT. Chiropractic adjustments: results of a controlled clinical trial in Egypt. Internation Review of Chiropractic 1985; Winter:58-60.

44 Sloop PR, Smith DS, Goldenberg E, Doré C. Manipulation for chronic neck pain: a double-blind controlled study. Spine 1982;7:532-5.

45 Nordemar R, Thörner C. Treatment of acute cervical pain: a comparative group study. Pain 1980;10:93-101.

46 Brodin H.Cervical pain and mobilization. Med Phys 1983:6:67-72.

47 Howe DH, Newcombe R. Manipulation of the cervical spine $7 R$ Gen Pract 1983;33:574-9.

48 Mealy $\mathrm{K}$, Brennan $\mathrm{H}$, Fenelon GCC Early mobilisation of acu whiplash injuries. BMF 1986;292:656-7.

9 Dickersin $\mathrm{K}$. The existence of publication bias and risk factors for its occurrence. $F A M A$ 1990;263:1385-9.

50 Greenland S, Reisbord LS, Haldeman S, Buerger AA. Controlled clinical trials of manipulation: a review and a proposal. F Occup Med 1980;22:670-6

51 Brunarski DJ. Clinical trials of spinal manipulation: a critical appraisa and review of the literature. F Manipulative Physiol Ther 1984;7:243-9.

52 Di Fabio RP. Clinical assessment of manipulation and mobilization of the lumbar spine: a critical review of the literature. Phys Ther 1986;66:51-4.

53 Koes BW, Bouter LM, van der Heijden GJMG, Knipschild PG. Physiotherapy exercises and back pain: a blinded review. $B M Y$ 1991;30:1572-6.

54 Freiman JA, Chalmers TC, Smith H, Kuebler RR. The importance of beta, the type II error and sample size in the design and interpretation of the randomized controlled trial. N Engl F Med 1978;299:690-4.

55 Pocock SJ, Hughes MD, Lee RJ. Statistical problems in the reporting of clinical trials. N Engl f Med 1987;317:426-32.

(Accepted 4 September 1991)

\title{
Dynamics of spread of HIV-I infection in a rural district of Uganda
}

Maria J Wawer, David Serwadda, Stanley D Musgrave, Joseph K Konde-Lule, Maako Musagara, Nelson K Sewankambo

Abstract

Objective-To define the geographical distribution of HIV infection and the community characteristics associated with HIV prevalence in a rural population of Uganda.

Design-Seroprevalence survey and interviews of the population aged 13 years and older in 21 randomly selected clusters.

Setting-Rural population of Rakai district, south west Uganda.

Subjects-1292 adults, of whom 594 men and 698 women gave a blood sample and answered the questionnaire.

Main outcome measures-HIV status determined by ELISA and western blotting in relation to community characteristics.

Results - The weighted seroprevalence of HIV for the district was $12.6 \%$ with prevalence by cluster varying from $1 \cdot 2 \%$ to $52 \cdot 8 \%$. Seroprevalence was highest in main road trading centres (men $26 \%$, women $47 \%$ ), intermediate in rural trading villages on secondary roads (men $22 \%$, women $29 \%$ ), and lowest in rural agricultural villages (men $8 \%$, women 9\%). For both men and women, multiple regression showed a strong negative association between cluster seroprevalence and the proportion of the population employed in agriculture $(\beta=-0.677$ for men, -0.807 for women). Among women, cluster seroprevalence increased with a higher proportion of the population reporting multiple sex partners $(\beta=0.814)$, external travel $(\beta=0.579)$, and injections $(\beta=0.483)$.

Conclusions-Community characteristics, particularly the proportion of the population in agriculture, are associated with HIV prevalence and can be used for targeting interventions. The seroprevalences of HIV suggest spread of infection from main road trading centres, through intermediate trading villages, to rural agricultural villages.

\section{Introduction}

Despite reports of high rates of HIV infection from clinical and urban settings in Africa ${ }^{1-6}$ data on rural populations are still scarce. Limited information suggests that HIV infection is spreading rapidly outside urban centres in some east and central African countries. ${ }^{78}$ As about $70 \%$ of the sub-Saharan African population does not live in cities, it is critical to understand the dynamics of the HIV epidemic in rural areas. Trading villages along main roads represent one obvious reservoir of infection outside the main urban areas; their importance as focuses of infection, related in part to commercial sex between local women and long distance truck drivers, has been reported in Uganda. ${ }^{910}$ However, the spread of HIV from these centres and the distribution of infection within agricultural areas have not been adequately defined. We attempted to define the spread of HIV in Rakai district, south western Uganda, where a random sample of residents have been enrolled in a longitudinal cohort study of HIV-I transmission and prevention.

\section{Subjects and methods}

SAMPLING

Rakai district has a population of 350000 , is about two hours by road from Kampala, and borders on northern Tanzania. Although Rakai is primarily rural, it is traversed by major roads that carry traffic from Tanzania, Rwanda, Kenya, and Lake Victoria (figure). The district contains 780 level one resistance committees, which are the smallest administrative units in 

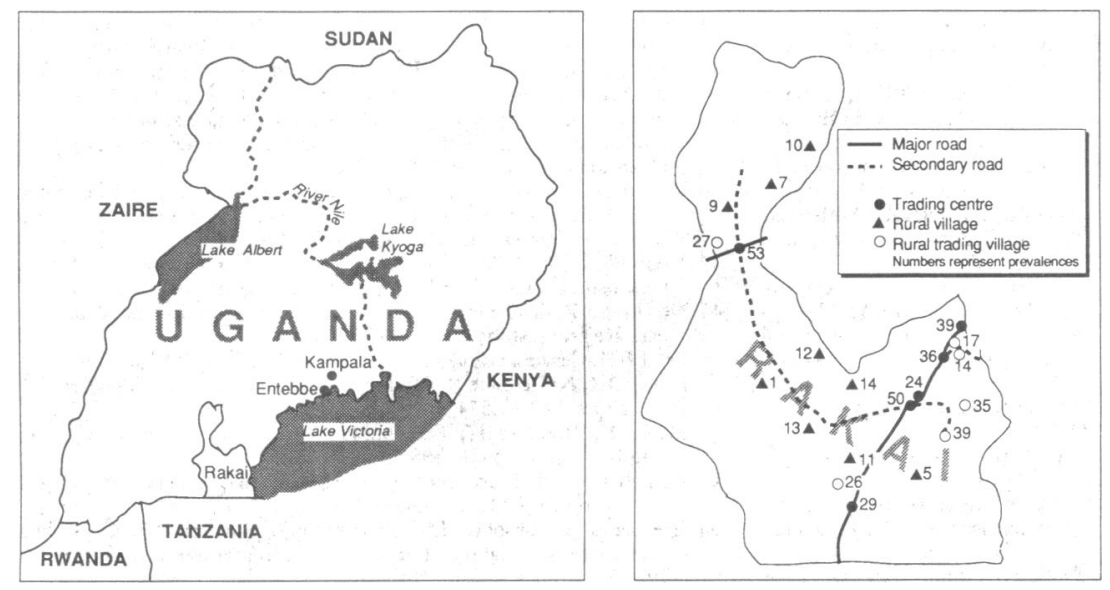

Maps (left) of Uganda showing Rakai district and (right) of Rakai district showing geographical distribution of clusters and prevalence of HIV-I infections in each cluster

Uganda, each having about 100 households. Twenty one resistance committees were randomly selected for the study: as there are fewer trading centres than rural villages in Rakai, we proportionately oversampled the resistance committees in trading centres to ensure adequate representation of these potentially high prevalence communities.

In second stage sampling, one index household was identified at random in each selected resistance committee and this household plus 39 contiguous households were then enrolled into the study, giving a total of 840 households. A enumeration team listed all people resident in the household for at least three months of the year, regardless of whether they were present at the time of the visit (de jure population). Reasons for absence were recorded.

\section{DATA COLLECTION}

We then conducted a serological, knowledge, and behavioural survey of all people aged 13 years or older. After obtaining written informed consent we collected information on sociodemographic characteristics, sexual behaviour, and past and current symptoms suggestive of sexually transmitted disease (including genital ulceration and discharge) or HIV related illness. When an eligible subject was absent at the time of the survey two repeat visits were conducted over the course of two days.

Whole blood specimens taken by venepuncture were spun in a portable centrifuge, and the separated serum was frozen in liquid nitrogen $\left(-218^{\circ} \mathrm{C}\right)$. Samples were stored in liquid nitrogen for an average of seven days. They were subsequently taken to the Uganda Virus Research Institute in Entebbe, a World Health Organisation HIV reference laboratory, for storage at $-20^{\circ} \mathrm{C}$. Testing for HIV-I was conducted by senior technicians at the institute. Initial screening was carried out with a commercial enzyme linked immunosorbent assay (ELISA; Recombigen EIA, Cambridge Biosciences, United States). All samples testing positive and 200 randomly selected samples testing negative were analysed by a commercial western blot kit (Biorad, United States) to confirm the results. Specificity of the ELISA was determined to be $93.3 \%$ and sensitivity $98 \cdot 8 \%$.

\section{STRATIFICATION OF CLUSTERS}

Field observations and analysis of cluster characteristics suggested that there are three types of communities in Rakai: main road trading centres with shops, bars, and hotels that serve domestic and international traffic; rural agricultural villages; and a third intermediate group of rural trading villages. Trading villages are situated $2-10 \mathrm{~km}$ from main roads and receive no international traffic but are hubs for local communications and transport networks. They contain a limited number of small shops and bars which sell local unbottled beer but do not have any hotels and no recognised commercial sex workers or bar girls. On the basis of these observations and to further clarify the relation between geography, community characteristics, and seroprevalence of HIV we constructed a three stratum classification. Among the 21 clusters in the study, we classified six as main road trading centres, nine as rural agricultural villages, and six rural trading villages. The classification was based on a priori community characteristics and not on population seroprevalences.

\section{STATISTICAL METHODS}

Simple and multiple regression was used to identify associations between the cluster or stratum prevalence of HIV infection and the sociodemographic and behavioural characteristics of the cluster or stratum populations. " Confidence intervals for weighted population estimates were adjusted for design effects resulting from cluster sampling and intrahousehold aggregation. $^{12}$

\section{Results}

In the enumerated population 1927 people were aged 13 and older; this group was considered adult for study purposes. Of the adults, $1510(78 \cdot 4 \%)$ were present at the time of the survey. The most common reasons for absence were work away from home (235 $(56 \%)$ of those absent) and visits away from the village (130 (31\%)). Absence due to illness accounted for only seven cases (2\%). Among the adults present, $85 \cdot 6 \%$ (1292) answered the questionnaire and provided a blood sample.

Out of 1292 adult serum samples, $255(19.7 \%)$ tested HIV-I positive on ELISA and by western blotting. The prevalence of HIV among the 594 men was $14.8 \%$ and among the 698 women $23.9 \%$. We extrapolated HIV prevalences from our sample clusters to estimate the weighted seroprevalence for Rakai district. Based on our data $12 \cdot 6 \%$ (95\% confidence interval $8 \cdot 7 \%$ to $16.5 \%$; design effect 3.5 ) of adults in Rakai are positive for HIV antibodies.

The distribution of HIV infection by cluster varied from $1 \cdot 2 \%$ to $52 \cdot 8 \%$ (figure). Simple linear regression indicated that several community characteristics were significantly associated with HIV seroprevalence in the clusters. Stepwise multiple regression was used to determine which community characteristics were most strongly predictive of cluster seroprevalence (table I). For men the only significant variable was the percentage of the cluster population who did agricultural work, which was associated with decreased sero- N prevalence. For women the significant variables were $D$ the proportions of the cluster population employed in agricultural jobs (associated with lower seroprevalence) $N$ and the proportions reporting two or more sex partners N in the past five years, having travelled to Kampala or foreign countries, and reporting injections in the past year (associated with higher seroprevalence).

We also examined HIV seroprevalence patterns using the three stratum classification for the type of 70 cluster discussed earlier. Table II gives the sociodemographic and risk factor characteristics in the three strata. In addition to obvious differences, such as the presence or absence of hotels and bars and distance from main roads, there were other important socioeconomic differences among the strata. A substantial 8 proportion of the population in the main road trading centres lived in houses constructed with modern ô housing materials, had some education, and had $\rightleftharpoons$ occupations other than in agriculture. Travel outside the district was most common in the trading centre 
population. The proportion of the population in the rural trading villages reporting such characteristics was substantially lower than in the main road trading centres, but higher than in the rural agricultural clusters.

The proportions of people with risk factors for HIV infection also showed a gradient: the highest proportions of people reporting multiple sex partners and a history suggestive of sexually transmitted diseases were found in the roadside trading centres and the lowest in the rural agricultural clusters. HIV seroprevalence was $38.5 \%$ in the main road trading centres, $25.4 \%$ in the trading villages, and $8.6 \%$ in the agricultural villages (table II). Such gradients were found despite the fact that people in the trading centres and trading villages had greater knowledge of AIDS and modes of transmission and greater access to health care than those in agricultural areas. (For example, 98\% reported knowing of AIDS in the first two strata compared with $89 \%$ in the agricultural stratum.)

Table III gives the prevalences of HIV-I infection according to age and sex. Seroprevalence was higher among women than men, particularly in the roadside trading centres. This largely reflects the higher seroprevalences in women aged 13-19 and 20-34. The relative risks of infection were significantly increased in the main road and trading village strata compared with the rural agricultural stratum for both men and women (table IV). The relative risk of infection in the trading centres compared with the trading villages was also significantly increased for women (relative risk $=1 \cdot 6,95 \%$ confidence interval $1 \cdot 2$ to $2 \cdot 1$ ) but not for men $(1 \cdot 2,0 \cdot 8$ to $1 \cdot 8)$.

Stepwise multiple regression indicated that the stratum variable was strongly associated with seroprevalence for both men $(\beta=0.690, \mathrm{p}<0.001)$ and women $(\beta=0.838, \mathrm{p}<0.001)$. For females, after adjustment for stratum, there was also a significant association with the proportion of the population reporting multiple sex partners in the past five years $(\beta=0 \cdot 446, p<0 \cdot 01)$. Other variables associated with HIV seroprevalence in table I (agricultural work, travel, and injections) were not significant after adjustment for stratum of residence.

TABLE I-Multiple regression of cluster characteristics for HIV seroprevalence

\begin{tabular}{lcc}
\hline & \multicolumn{2}{c}{ Standardised $\beta$ coefficient } \\
\cline { 2 - 3 } Cluster characteristics & Men & Women \\
\hline In agricultural work & $-0 \cdot 677^{\star \star}$ & $-0 \cdot 807^{\star \star}$ \\
With $>$ two sex partners in past five years & NS & $0 \cdot 814^{\star \star}$ \\
Travelling to Kampala or foreign countries & NS & $0 \cdot 579^{\star}$ \\
Reporting injections in the past year & NS & $0 \cdot 483^{\star}$ \\
\hline
\end{tabular}

${ }^{\star} \mathrm{p}<0.01,{ }^{\star \star} \mathrm{p}<0.001$

TABLE II - Sociodemographic characteristics of study population according to stratum of cluster. Figures are numbers (percentages) unless otherwise stated

\begin{tabular}{lccc}
\hline & $\begin{array}{c}\text { Main road trading } \\
\text { centre }\end{array}$ & Rural trading village & $\begin{array}{c}\text { Rural agricultural } \\
\text { village }\end{array}$ \\
\hline $\begin{array}{l}\text { No of clusters } \\
\text { No of households }\end{array}$ & 6 & 6 & 9 \\
No of poeple & 236 & 238 & 359 \\
$\begin{array}{l}\text { Mean distance of clusters to main road }(\mathrm{km}) \\
\text { Presence of lodge (hotel) }\end{array}$ & $6(100)$ & 346 & 660 \\
Presence of bar & $6(100)$ & $4 \cdot 5$ & \\
$\begin{array}{l}\text { Households with modern building materials } \\
\text { Working in agriculture }\end{array}$ & $224(95 \cdot 0)$ & $185(77 \cdot 7)$ & $120(33 \cdot 3)$ \\
Working in bar or hotel or as driver & $85(29 \cdot 7)$ & $226(65 \cdot 2)$ & $196(86 \cdot 6)$ \\
Any education & $30(10 \cdot 4)$ & $10(2 \cdot 9)$ & $1(0 \cdot 4)$ \\
Travel to Kampala or foreign countries: & $252(88 \cdot 1)$ & $242(69 \cdot 9)$ & $173(50 \cdot 0)$ \\
$\quad$ Men & $31(27 \cdot 7)$ & $13(8 \cdot 5)$ & $28(8 \cdot 5)$ \\
$\quad$ Women & $26(14 \cdot 9)$ & $13(6 \cdot 7)$ & $16(4 \cdot 8)$ \\
Two or more sex partners in past five years: & & & $108(33 \cdot 0)$ \\
$\quad$ Men & $69(61 \cdot 6)$ & $65(42 \cdot 5)$ & $30(9 \cdot 0)$ \\
$\quad$ Women & $52(30 \cdot 0)$ & $29(15 \cdot 0)$ & $38(10 \cdot 9)$ \\
History of sexually transmitted disease & $58(20 \cdot 3)$ & $48(13 \cdot 9)$ & $15(4 \cdot 2)$ \\
Sex for pay or gift & $29(10 \cdot 2)$ & $25(7 \cdot 3)$ & $8 \cdot 6(1 \cdot 2-14 \cdot 0)$ \\
HIV seroprevalence (range of clusters) $(\%)$ & $38 \cdot 5(24 \cdot 2 \cdot 52 \cdot 8)$ & $25 \cdot 4(14 \cdot 0-38 \cdot 5)$ & \\
\hline
\end{tabular}

TABLE III-Prevalence (\%) of HIV-I infection by age, sex, and stratum of cluster

\begin{tabular}{lccc}
\hline Age goup & $\begin{array}{c}\text { Trading } \\
\text { Centre }\end{array}$ & $\begin{array}{c}\text { Rural trading } \\
\text { village }\end{array}$ & $\begin{array}{c}\text { Rural } \\
\text { agricultural } \\
\text { village }\end{array}$ \\
\hline Men: & & & \\
$13-19$ & $0(0 / 29)$ & $3(1 / 30)$ & $1(1 / 69)$ \\
$20-34$ & $39(22 / 57)$ & $40(21 / 53)$ & $18(18 / 100)$ \\
$35-49$ & $38(6 / 16)$ & $30(9 / 30)$ & $9(7 / 74)$ \\
$50+$ & $10(1 / 10)$ & $6(2 / 36)$ & $0(0 / 66)$ \\
Unknown & & $0(0 / 4)$ & $0(0 / 20)$ \\
Women: & $50(20 / 40)$ & $18(8 / 45)$ & $9(6 / 68)$ \\
$13-19$ & $57(52 / 91)$ & $42(33 / 79)$ & $15(19 / 131)$ \\
$20-34$ & $28(7 / 25)$ & $25(10 / 40)$ & $8(6 / 71)$ \\
$35-49$ & $17(2 / 12)$ & $23(3 / 13)$ & $0(0 / 37)$ \\
$50+$ & $0(0 / 6)$ & $6(1 / 16)$ & $0(0 / 24)$ \\
Unknown & & & \\
\hline
\end{tabular}

*Most people of unknown age appeared to belong to older age groups.

TABLE IV-Seroprevalence of HIV-I and relative risk by stratum of cluster and sex

\begin{tabular}{|c|c|c|c|}
\hline & No of subjects & $\begin{array}{c}\text { No (\%) infected } \\
\text { with HIV }\end{array}$ & $\begin{array}{c}\text { Relative risk } \\
\text { (95\% confidence } \\
\text { interval) }\end{array}$ \\
\hline \multicolumn{4}{|l|}{ Men: } \\
\hline Trading centre & 112 & $29(26)$ & $3 \cdot 3(2 \cdot 0$ to $5 \cdot 1)$ \\
\hline Trading village & 153 & $33(22)$ & $2.7(1.7$ to $4 \cdot 3)$ \\
\hline Agricultural village & 329 & $26(8)$ & $1 \cdot 0$ \\
\hline \multicolumn{4}{|l|}{ Women: } \\
\hline Trading centre & 174 & $81(47)$ & $5.0(3.5$ to $7 \cdot 4)$ \\
\hline Trading village & 193 & $55(29)$ & $3.0(1.9$ to 4.5$)$ \\
\hline Agricultural village & 331 & $31(9)$ & 1.0 \\
\hline
\end{tabular}

\section{Discussion}

Although several surveys of HIV seroprevalence have been conducted in rural areas of sub-Saharan Africa, none provided detailed information on differences in rates of HIV infection within rural populations, or on the association of seroprevalence with community characteristics. This information is needed to understand the spread of HIV in rural Africa and to determine the most effective intervention strategies.

The Rakai district weighted seroprevalence of $12 \cdot 6 \%$ is comparable with the preliminary result of the Ugandan national serosurvey for rural central region $(12 \cdot 1 \%)$, in which Rakai is situated (Minister of Health, Republic of Uganda, press conference 30 November 1989). The national serosurvey does not, however, permit detailed analysis of differences in seroprevalence within rural populations.

We found substantial variations in HIV seroprevalence despite the fact that the population of Rakai district has probably been exposed to the infection for almost a decade. ${ }^{13}$ In the absence of contact tracing, the spread of HIV infection cannot be directly observed. None the less, it is possible to infer the spread of infection by examining differences in HIV sero- م prevalence by cluster and by type of cluster. The $\rightarrow$ differences noted between main road trading centres, rural trading villages, and rural agricultural villages (figure and table III) suggest that HIV transmission tends to follow lines of communication along main and secondary roads, as has been found with other sexually transmitted diseases. ${ }^{14} 15$ The main road trading centres seem to act as focuses of infection. This is partly associated with domestic and international trucking and commercial sex in bars and hotels, ${ }^{1016}$ which is reflected in the disproportionately high seroprevalence among women compared with men. The rural trading villages located on secondary roads are not directly accessible to international traffic and are not noted as centres of commercial sex but may provide a conduit or secondary locus for the spread of HIV to the more rural villages, which have the lowest seroprevalence.

Multiple regression identified strong associations between a higher proportion of the population engaged in agricultural work and lower cluster seroprevalence. 
Similarly, there was a strong association between seroprevalence and type of cluster. Behavioural risk factors, such as the proportion of people in each cluster reporting two or more sexual partners, external travel, and injections, were correlated with higher seroprevalence in women but not in men (table I). Thus residence in an agricultural community reduces the risk of HIV infection, but for women the protective effect of rural residence may be countered by factors such as community levels of external travel and multiple sex partners, behaviours which are predominantly reported by men. The data suggest that the introduction of HIV into rural communities may be largely associated with male behaviour, including the infection with HIV during travel outside the cluster and contact with multiple partners on return. Levels of education, soçioeconomic status, and knowledge of AIDS were higher in the trading centres and trading villages than in the agricultural villages. The pattern of HIV infection is thus not due to greater availability of information or services in low prevalence rural communities.

Further prospective studies will permit estimates of patterns of HIV infection and transmission. For the present, categorising rural Ugandan communities into three strata provides a useful approach to identify high risk communities by their characteristics and potentially to develop targeted interventions permitting more effective use of limited resources. Trading centres and rural trading villages should be considered targets for intensive preventive interventions both for their benefit and potentially to prevent spread of infection from these high prevalence communities to neighbouring lower prevalence rural areas.

We thank Dr S Okware, Ugandan AIDS Control Programme; Drs Sampala, B Biryawaho, R Downing, Ugandan Virus Research Institute; Dr S Berkley, Rockefeller Foundation; Drs Z Stein, M Begg, Columbia University; Ms M F
Lafontaine; Dr R H Gray, Mr M Emerson, Johns Hopkins University; and Dr J Kaplan, Centers for Disease Control. This study was supported by National Institute of Allergy and Infectious Diseases, National Institutes of Health (R01A129314-01); Research Division, Office of Population, United States Agency for International Development (cooperative agreement DPE-3030-A-00-4049); Rockefeller Foundation.

1 N'Galy B, Ryder RW, Bila K, Mwandagalirwa K, Colebunders RL, Francis $H$, et al. Human immunodeficiency virus infection among employees in an African hospital. N Engl F Med 1988;319:1123-7.

2 Kreiss JK, Koech D, Plummer FA, Holmes KK, Lightfoote M, Piot P, et al. AIDS virus infection in Nairobi prostitutes: spread of the epidemic to east Africa. $N$ Engl I Med 1986;314:414-8

3 Piot P, Plummer FA, Rey MA, Ngugi EN, Rouzioux C, Ndinya-Achola JO et al. Retrospective seroepidemiology of HIV in Nairobi populations. Infect Dis 1987;155:1108-12.

4 De Cock KM, Porter A, Odehouri K, Barrere B, Moreau J, Diaby L, et al. Rapid emergence of AIDS in Abidjan, Ivory Coast. Lancet 1989;ii:408-11.

Dolmans WMV, van Loon AM, van den Akker R, Mulder DW, Shau JF, Mbena E, et al. Prevalence of HIV-1 antibody among groups of patients and healthy subjects from a rural and urban population in the Mwanza region, Tanzania. AIIDS 1989;3:297-9.

6 Denis F, Barin F, Gershy-Damet G, Rey JL, Luhillier M, Mounier M, et al. Prevalence of human T-lymphotrophic retroviruses type III (HIV) and type V in Ivory Coast Lancet 1987; i:408-11.

7 de Lalla F, Rizzardini G, Santoro D, Galli M. Rapid spread of HIV infection in a rural district in central Africa. AIDS 1988;2:317.

8 Killewo J, Nyamurekunge K, Sandstrom A, Bredberg-Raden U, Wall S, Mhalu F, Biberfeld G. Prevalence of HIV-1 infection in the Kagera region of Tanzania: a population-based study. AIDS 1990;4:1081-5.

9 Naamara W, Plummer F. Cross sectional study of HIV infection in SW Uganda. In: Proceedings of the second international conference on AIDS in Africa, Naples, 1988. Abstract 37.

10 Carswell JW. HIV infection in healthy persons in Uganda. AIDS 1987; 223-7.

11 Hosmer DW, Lemeshow S. Applied logistic regression. New York: John Wiley and Sons, 1989.

12 Cochran WG. Sampling techniques. 3rd ed. New York: John Wiley and Sons, 1977.

13 Serwadda D, Mugerwa RD, Sewankambo NK, Lwegaba A, Carswell JW, Dirva GB. Slim disease, a new disease in Uganda and its association with HTLV-III infection. Lancet 1985;ii:849-52.

14 Wilcox RR. Venereal diseases in the Pacific Islands: Papua New Guinea Br f Vener Dis 1980;56:277-81.

15 Plorde DS. Sexually transmitted disease in Ethiopia: Social factors contributing to their spread and implications for developing countries. $\mathrm{Br} \mathcal{F}$ Vener $D i$ to their spread and

16 Carswell JW, Lloyd G, Howells J. Short communication: prevalence of HIV-I in east African lorry drivers. AIDS 1989;3:759-61.

Accepted 30 August 1991

\section{Serum sialic acid concentration and smoking: a population based study}

\section{Centre for Public Health \\ Research, S-651 82 \\ Karlstad, Sweden \\ Gunnar Lindberg, MD, senior \\ physician}

\section{Department of \\ Community Health}

Sciences, University of

Lund, Malmö, Sweden

Lennart Råstam, MD, senior

lecturer in family medicine

Bo Gullberg, MA, senior

lecturer in medical statistics

\section{Radiumhemmet,}

Karolinska Hospital,

Stockholm, Sweden

Gunnar A Eklund, PHD,

professor of epidemiology,

department of cancer

epidemiology

Sven Törnberg, MD,

consultant oncologist,

department of general

oncology

Correspondence to:

Dr Lindberg.

B.11: 1991:303:1306-7

\section{Gunnar Lindberg, Lennart Råstam, Bo Gullberg, Gunnar A Eklund, Sven Törnberg}

We recently showed that the serum sialic acid concentration predicts mortality from cardiovascular diseases among men and women independently of blood pressure, total cholesterol concentration, and body mass index. ${ }^{1}$ The relation between sialic acid concentration and mortality from cardiovascular disease is unclear. Smoking is a possible confounder that has not been investigated. We therefore investigated whether smoking habits influence the sialic acid concentration.

\section{Subjects, methods, and results}

The Värmland survey, in which sialic acid concentrations were measured in 97468 subjects in 1962-5, has been described.' : The methods of Hess et al and Svennerholm were used to determine the sialic acid concentration in 1962-3 and 1963-5, respectively. ${ }^{3+}$ In 1963 a Swedish national postal survey of smoking habits was undertaken. ${ }^{5}$ A random sample of roughly $1 \%$ of the adult Swedish population, stratified for age, was asked about their present and past smoking habits. The response rate was $94 \%$.
For the present study we used an algorithm based on the grams of tobacco consumed in 1963 as cigarettes, cigars, or pipe tobacco to quantify the amount smoked. We defined smokers as those who had reported smoking cigarettes, cigars, or a pipe daily. We defined non-smokers as those who had never smoked. Computerised records from subjects who participated in both studies were linked by using the personal identification number. We used analysis of variance and analysis of covariance for statistical testing. Significance was assumed at $\mathrm{p}<0.05$.

A total of 518 men and 504 women participated in both the Värmland survey and the survey of smoking habits in Sweden. Altogether 220 men and 62 women were regular smokers, and 116 men and 383 women had never smoked.

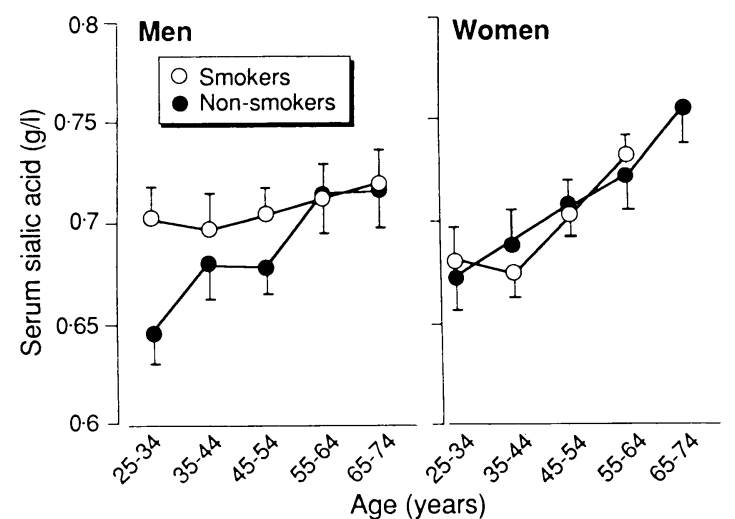

Serum sialic acid concentration in men and women according to smoking habit and age 